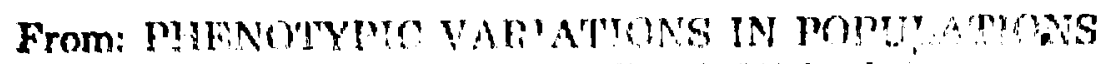

Pa

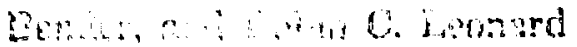

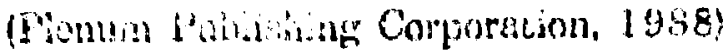

BNL --40909

DE88 007051

RELEVANCE OF PHENOTYPIC VARIATION IN RISK ASSESSMENT:

THE SCIENTIFIC VIELPOINT

Richard B. Setlow

Biology Department

Brookhaven National Laboratory

Upton, NY 11973

\title{
INTRODUCTION
}

Everyone knows that people vary widely in their responses to local environmental changes such as heat or cold, pollen, rotation, or high altitudes. We know a great deal about such responses; how they depend ort an individual's previous exposures, lifestyle and age, for example. A much more difficult problem, because of the absence of good, human data, is the evaluation of dose-response curves for exposures to radiations or environmental chemicals. If we had such data, it would be possible to estimate risk from exposure; unfortunately, almost all the human data that exist are not the result of chronic exposures, but come from acute, high doses. Likewise, animal data almost always represent effects at high doses. Thus the problem is how to extrapolate from h1gh doses to low doses. One can either do the extrapolation arbitrarily or take some scientific approach to the problem. One such approach is to understand the mechanisms at the molecular level responsible for the observed effects and then to use this understanding to construct theories permitting the extrapolation from high to low doses. Therefore, what we need are good blological theorles. However, superimposed on such theories must be an analysis of the variability in the responses of the human population. These variabilities can be thought of as subsets within rather broad categories, as indicated in Table 1. Thus, women cannot be lumped with men because, among other things, they have a different hormonal status and hence are more susceptible to breast cancer; similarly, only men have prostrate cancer. We know that older Individuals usually are less able to cope with stress than younger ones and moreover, they seem less proficient in DNA repair than are younger people ${ }^{1}$.

\section{Skin Cancer}

Almost all skin cancer in fair-skinned people is associated with sunlight exposure: usually the prevalence of skin cancer in pigmented ind1viduals. is one or two orders of magnitude less because pigment in superficial layers of their skin absorbs the incident sunlight, so shielding and protecting the underlying growing cells. As a result, falr-skinned people will be much more affected than pigmented individuals by any depletion of stratospheric ozone, with the attendant increase in Uv radiation at the earth's surface that may result from chemical emissions into the atmosphere $^{2}$. Thus, at the level of pigmentation, it is clear that minimizing the ozone depletion is in the best interest of Caucasians. However, the 
Table 1: Subsets with Variabllity in Response Wl thin the lluman population

\author{
1. Women versus inen \\ 2. Old versus young \\ 3. Dark skin versus fair skin \\ 4. Repair proficiency versus repair deficiency \\ 5. Proficient carcinogen metabolizer versus \\ deficient me tabolizer
}

white population represents a minority of the world's inhabitants, and there is a significant ethical problem in denying the majorlty of people the benefits of such chemicals because of concerns for their effects upon the minority.

Even in the fair-skinned population there are wide variations in sensitivity to UV-radiation. Genetic analysis of cancer-prone familles and studies on their cells in culture showed that several cancer-prone syndromes are closely associated with deficits in the ability of cells to repair exogenous, and possibly, endogenous damage to their DNA ${ }^{3} 4$. The best understood of these syndromes is xeroderma pigmentosum (XP) a syndrome in which homozygous individuals are extraordinarily sensitive to sunlightinduced cancer--approximately 10,000-fold more sensitive than unaffected people ${ }^{5}$. The frequency of the homozygous condition in the United $S$ tates is approximately 1 in 250,000 . Hence, the condition is not an overwhelming concern for public health. However, since the various types of XP cells investigated seem, on the average, to be only about $20 \%$ as proficient as normal cells in the repalr of ultraviolet damage, we see that an $80 \%$ defect in repair results in a 10,000-fold enhancement in the susceptibility to a particular exogenous agent, ultraviolet radiation. The important question is, What would be the effect of a 10 or a $20 \%$ defect in DNA repair? Could such a relatively small defect, one within the range of what we would call the normal distribution, increase susceptibility by as much as 10-fold? Note that the variations observed in repair-deficlent syndromes may far outweigh those of differences in pigmentation, so that within each pigmentation group there is a large variation in repalr capabilities. We know that there are extensive variations in repair capacity, as measured by the ability of cells in culture to repair ultraviolet damage ${ }^{6}$. For example, unscheduled DNA synthesis, a measure of DNA repair, in epidermal cells varies as much as 3-fold among individuals of similar ages from whom the epilermal cells were obtained. In addition, the average repair decreases a lmost 3-fold from age 20 to 80 .

The dose-response curves for skin cancer in animals and the estimated curves from epidemlological studies on humans are excellent. In the case of humans, these are some of the best dose-response curves avallable, because the number of new cases of skin cancer per year in the United States is close to 500,000 . The reason for this large number probably is very high doses that sunlight provides compared to other environmental insults.

\title{
Iontzing Radiation
}

Ataxia telanglectasia (AT) is a complicated homozygous recessive condition in which the affected individuals and their cells are extraordinarily sensitive to the cytotoxic effects of ionizing radiation. The nature of the repair defect in $A T$ is not known; the disease is more commmon than XP, affecting in the neighborhood of 1 person per 40,000 in the United 
Table 2. Estlmated INA Damage Rates apd Repair Rates in lluman Celis at $37^{\circ} \mathrm{Cl}$

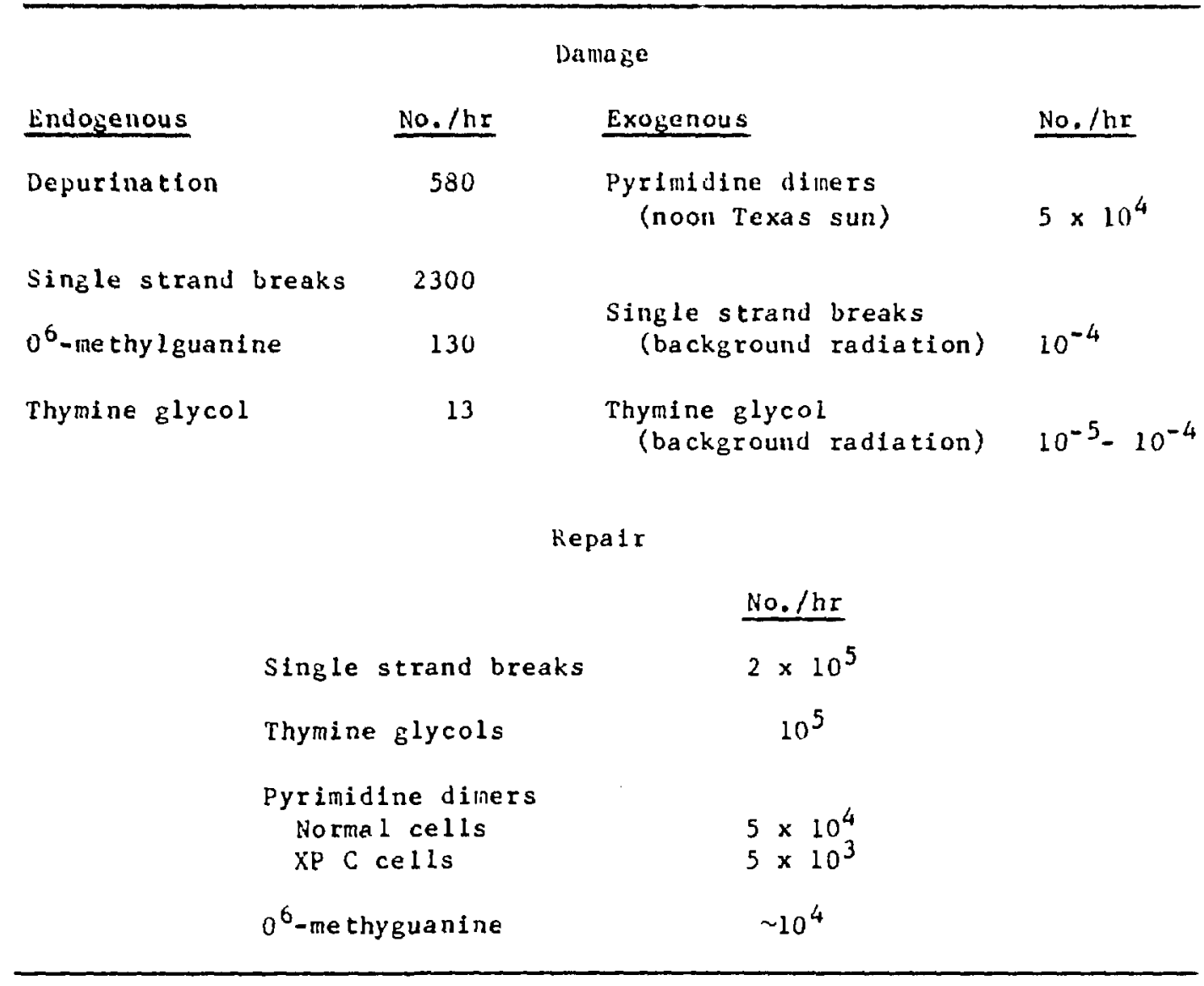

States and hence, the number of heterozygotes in the population is approximately 1\%. A significant fraction of the latter group may be at increased risk, especially when one considers the observations in several studies that the cells of AT heterozygotes are more sensitive than normal to ionizing radiation and to chemicals that cause DNA strand breaks 8,9 .

Lacking a direct measure of DNA repair in AT, a convenient measure is the cytotoxic sensitivity given by $D_{O}$, the reciprocal of the slope of the survival curve (a graph of logarithm of survival versus radiation dose). Values of $D_{0}$ have been measured for a large number of fibroblast strains obtalned from normal individuals, from AT homozygotes and AT heterozygotes. The results from a rumber of surveys show that there is a large difference between normal cells and AT cells, that in normal cells there is a wide distrlbution in sensitivities, and that, on the average, $A T$ heterozygotes fall somewhere on the low side of the normal distribution $6,8,9$. If we had confidence in using such data to predict dose-response curves for people, we could construct the curves associated with ach segment of the population and then estimate risks for these individual segments.

Endogenous vs. Exogenous Damage

When most of us think of hazards or risks, we think of bombs, nuclear reactors, food additives and toxic waste dumps. However, the biggest source of damage to the DNA of our cells results from endogenous chemical reactions at $37^{\circ}$. Table 2 compares the amount of DNA damage per hour per mammalian cell resulting from endogenous reactions and from exogenous 
ones 1 . The rate of introduction of endogenous damage inco DNA is so large that if it were not repaired, approxillately $10 \%$ of the INNA bases per cell would be damaged in a 70-year lifetime. One would conclude from such a number either that DNA is not the genetic material, nor does it form the basis for transcrlption, or that there are potent DNA repalr mechanisms, The latter is the case. Table 2 also indicates some of the rates of repalr of damage. A comparison of these numbers indicates that endogenous damage is much more important than exogenous damage, except for that produced by exposure to ultraviolet radiation. The amount of damage resulting from background ionizing radlation is negligible compared to the damage resulting frum endogenous reactions. Indeed it is these reactions that are probably responsible for a large fraction of the background rates of cancer in the human population.

A special case in which the repair reaction is much faster than the reaction introducing the damage is the production and repair of $0^{6}$-methylguanine. This mutagenic, and presumably carcinogenlc, adduct is introduced into DNA as a by-product of an essential metabolic reaction. Its repair is intriguing, in that the repair reaction is a stochiometric one. The repair protein can repair only one adduct, and upon effecting this, it is inactivated ${ }^{4}$. Although this system works rapidly, it is soon used up and there is no further repair until new protein is made. On this basis one would expect that the dose-response curve for effects arising from this particular adduct have a concave upwards shape. At low doses repair is very effective, and litile damage persists. At high doses, the repair system becomes saturated and the crucial adduct can persist long enough to cause mutations in dividing cells. Indeed, this seems to be the case for mutations induced in male mice treated with the alkylating agent ethylnitrosourea 10 . The induction of mutants is a function of injected concentration and the response curve is concave upward, and appears as if it has a threshold that would not be detectable by extrapolation from high doses.

Smoke contains alkylating agents derived from tobaccoll: presumably the DNA adducts from such alkylating agents are repaired effectively. However, at high levels of $0^{6}$-alkylguanine, the repair system may be saturated and, indeed, it was observed that cells washed out of the lungs of smokers have a significantly lower repair capacity for $0^{6}$-methylguanine than cells washed out of the lungs of nonsmokers ${ }^{12}$. The decreased repair observed in smokers could either be the result of the inactivation of repair protein during the repair reaction itself, or could result from the fact that smoke contains oxidizing agents which oxidize the crucial SH-group responsible for the activity of the repair protein. In either event, in smokers we have a situation in which smoke contains nitrosamines, both alkylating agents and carcinogens, and the lungs of smokers have less repaif activity. Here we have an environmental agent that not only reacts with DNA but tends to destroy the repair activity that would ameliorate the effects of DNA damage.

\section{CONCLUSION}

A number of examples have been presented indicating the types of variations that may be expected in the responses of the human population to deleterious agents of an endogenous or exogenous nature. If one assumes that the variations in repair in the normal population are reflected in large variations in carcinogenic risk per unit of exposure, then the doseresponse curves at low doses cannot be extrapolated from high doses without knowing the distribution of sensitivities among humans. The probability of determining this range by epidemiological studies on a random population by small. On the other hand, the probability of determining the range by careful genetic and molecular studies appears high enough so that such 
experlments now are betng carried out. They cannot be carried out on real populations, using chronic exposures. Hence, the ability to estimate doseresponse relations in the low dose region on human populations can only be by making theoretical constructs that, in turn, are dependent on fundamental research.

\section{REFERENCES}

1. R. R. Tice and R. B. Setlow, DNA repair and replication in aging organisms and cells, in: "Handbook of the Biology of Aging, second edition," C. E. Finch and E. L. Schneider, eds., Van Nostrand Relnhold, New York (1985).

2. National Research Council, "Causes and Effects of Stratospheric Ozone Reduction: An Update," National Academy Press, Washington (1982).

3. R. B. Setlow, Repair deficient human disorders and cancer, Nature $271: 713(1978)$.

4. E. C. Frledberg, "DNA Repa1r,"W. H. Freeman, New York (1985).

5. K. H. Kraener, M. M. Lee, and J. Scotto, DNA repair protects against cutaneous and internal neoplasia: Evidence from xeroderma pigmentosum, Carcinogenests 5:511 (1984).

6. R. B. Setlow, Variations in DNA repair among humans, in: "Human Carcinogenesis," C. C. Harris and H. N. Autrup, eds., Academic Press, New York (1983).

7. E. G. Nette, Y.-P. Xi, Y. -K. Sun, A. D. Andrews, and D. W. King, A correlation between agling and DNA repair in human epidermal cells, Mech. Age. Deve lop. $24: 283$ (1984).

8. Y. Shiloh, E. Tabov, and Y. Becker, The responses of ataxia-telangiectasia homozygous and heterozygous skin fibroblasts to neocarzinostatin, Carcinogenesis 3:815 (1982).

9. H. Nagasawa, K. H. Kraemer, Y. Shiloh, and J. B. Itttle, Detection of ataxia telanglectasia heterozygous cell lines by post irradiation cumulative labeling index: Heasurements with coded samples, Cancer Res., 47:398 (1987).

10. W. L. Russe11, P. R. Hunsicker, G. D. Raymer, M. H. Steele, K. F. Stelzner, and H. M. Thompson, Dose-response curve for ethylnitrosourea-induced specific-locus mutations in mouse spermatogonia, Proc. Nat1. Acad. Sc1. USA, 79:3589 (1982).

11. D. Hoffmañn, J. D. Adams, K. D. Brunnemann, and S. S. Hecht, Assessment of tobacco-specific N-nitrosamines in tobacco products, Cancer Res., 39:2505 (1979).

12. E.-H. Cao, R. B. Setlow, and A. Janoff, Alkylation repair activity in the lung macrophages of smokers and nonsmokers, Annals N.Y. Acad. Sci., 459:269 (1985). 